\title{
Humanismo cívico y tradición clásica en los albores republicanos de Chile $^{1}$
}

\author{
María Gabriela Huidobro SALAzAR \\ Universidad Andres Bello, Chile \\ mhuidobro@unab.cl
}

Recepción: 9 de julio de 2014 / Revisión: 14 de octubre de 2014

Aceptación: 13 de noviembre de 2014 / Publicación: Diciembre de 2015

\section{RESUMEN}

Las primeras décadas del siglo XIX constituyeron para Chile un periodo de cambios profundos, cuyo principal resultado se visibilizó en el proceso y consolidación de su independencia frente a la tutela española en 1818. Sus alcances no sólo supusieron una revolución desde una perspectiva militar o política, sino también una renovación del horizonte cultural, al menos por parte de la comunidad de patriotas letrados, en un esfuerzo por distanciarse ideológicamente de la monarquía, con el desafío implícito de fundar sobre bases legítimas y universalmente reconocibles un nuevo orden para Chile. La matriz de inspiración de tales esfuerzos suele asociarse a los ejemplos revolucionarios -francés y norteamericanoque precedieron al proceso de emancipación en Hispanoamérica, así como a los modelos discursivos del liberalismo ilustrado. Sin embargo, una nueva lectura de los textos escritos por los criollos que lideraron el proceso independentista de Chile, puede develar igualmente la relevancia de la tradición clásica como modelo para la configuración y legitimación de los primeros proyectos republicanos, admiradores especialmente de los ideales del republicanismo, tal como intentaremos demostrar en el presente estudio.

Palabras clave: Tradición clásica, humanismo cívico, republicanismo, Independencia de Chile, patriotas, Chile, siglo XIX.

\section{Civic Humanism and the Classical Tradition in the Early Republic of Chile}

\begin{abstract}
The first decades of the 19th century constituted a period of profound change for Chile, the principal results of which were to be seen in the consolidation of the process of independence from Spanish dominion in 1818. The consequences were not limited to a revolution of military and political nature; they also included a renovation of the cultural panorama -at least among the educated patriots who made an effort to distance themselves ideologically from the Monarchy-, with the implicit challenge of establishing a new order for Chile, based on legitimate and universally recognizable foundations. The inspirational framework for these efforts is usually associated with other revolutionary examples -France and the United States- that preceded the emancipation processes in Spanish America, as well as with the discourses of illustrated liberalism. As we will attempt to demonstrate in this study, a new reading of the texts written by the Creoles that lead the Chilean independence process may, nonetheless, also reveal the relevance of the classical tradition as a model for the configuration and legitimization of the first Republican projects that especially admired the ideals of Republicanism.
\end{abstract}

\footnotetext{
1 Este artículo se enmarca en el Proyecto de Investigación Fondecyt No 11130585, Chile.
} 
Keywords: Classical Tradition, Civic Humanism, Republicanism, Independence of Chile, Patriots, Chile, 19th Century.

SumARIO: 1. Una comunidad de patriotas letrados. 2. Lecturas y modelos intelectuales de los patriotas. 3. Tradición clásica en Chile a comienzos del siglo XIX. 4. Humanismo cívico en el proyecto de los patriotas letrados. 5. Consideraciones finales. 6. Fuentes. 7. Referencias bibliográficas.

\section{UNA COMUNIDAD DE PATRIOTAS LETRADOS}

La sociedad chilena de fines del siglo XVIII y principios del XIX había consolidado una organización que, aunque dirigida políticamente por dignatarios españoles, estaba encabezada por una comunidad criolla investida de prestigio social y poder económico ${ }^{2}$. Se trataba de una oligarquía que hasta las primeras acciones del proceso emancipador, se mantuvo leal a la monarquía hispana, pero educada en la tensión entre un contexto heredero de un sistema formativo colonial, que poco difería del modelo educativo escolástico, y otro contexto referencial, que la inspiraba desde Europa con ideas ilustradas y lecturas renovadas ${ }^{3}$.

En este sentido, el universo cultural de estos criollos escapaba de los patrones delimitados por el sistema educativo de la colonia. La mayor parte de los líderes independentistas chilenos tuvieron la oportunidad de viajar al extranjero para realizar estadías prolongadas o bien directamente como estudiantes. Tales contactos influirían decisivamente en la formación de cada uno de ellos ${ }^{4}$.

José Antonio de Rojas (1732-1817) ofrece un primer ejemplo. Nacido en Santiago, estudió en la Real Universidad de San Felipe, pero viajó luego a Perú y posteriormente, en 1772, a España, donde permaneció hasta 1778. En ese contexto, se maravilló de la riqueza cultural y de las tendencias intelectuales racionalistas europeas, lamentándose por la notoria diferencia que se sufría en Chile:

Cuando yo veo aquí (con ser que esta es la porción mas abandonada i despreciable de la Europa) los seminarios, así para las ciencias, como para el arte militar, las academias de escultura, pintura i arquitectura, i otras oficinas donde a este animal-hombre le enseñan todo lo que en cualquiera otra parte es capaz de saber, digo entre mí: si me pusieran a escoger entre todas las grandezas, i uno de los colejios, yo abandonaría

2 Las estimaciones sobre la población chilena hacia 1800 calculan el número de habitantes entre los quinientos mil y un millón, sobre la base de los censos realizados entre 1778 y 1812. Más allá de las diferencias estimativas, la oligarquía criolla - tal como la define Simon Collier- estaba compuesta por aproximadamente doscientas familias, radicadas sobre todo en la zona de Santiago y, en menor medida, en las ciudades de La Serena, Talca y Concepción. ColLIER, 2012, pp. 37-40.

$3 \mathrm{Al}$ alero de los seminarios o colegios eclesiásticos, de la Real Universidad de San Felipe y del Colegio de San Carlos, la educación del siglo XVIII en Chile había sostenido una formación centrada en los estudios del latín, de la teología y del derecho. Por tal motivo, este modelo educativo se volvería posteriormente objeto de crítica por parte de quienes liderarían el proceso emancipador, al haberse mantenido lejos de los procesos de cambio y desactualizado ante los modelos que se consideraban progresistas desde una óptica liberal. AmUNÁtegui, 1889, p. 2; Collier, 2012, p. 42; Subercaseaux, 2000, pp. 10-11.

4 Amunátegui, 1889, p. 7. 
aquellas, i volveria contentísimo a mi país con uno de éstos. Pero esto es soñar despierto. Aún no ha llegado el tiempo de que amanezca la racionalidad en la América 5 .

Camilo Henríquez (1769-1825), protagonista político e intelectual del proceso independentista, ofrece otro ejemplo. Nacido en Valdivia el 20 de julio de 1769, fue enviado por sus padres a educarse en Santiago, en el Colegio Carolino, y luego, en 1784, a Lima, donde ingresó a uno de los mejores colegios del virreinato para entonces, la Orden de los Ministros de los Enfermos Agonizantes de San Camilo de Lelis. Allí pudo vincularse a la sociedad letrada de Lima, formada igualmente en contacto con las tendencias modernas europeas, y tuvo acceso a la lectura de autores racionalistas e ilustrados, como Voltaire, Montesquieu y Rousseau. Por este motivo, habría estado inmiscuido en un proceso de la Inquisición hacia 1809, pese a que se desconozcan los detalles específicos del caso ${ }^{6}$.

Por su parte, Manuel de Salas (1754-1841) y Juan Egaña (Lima, 1769-1836), líderes políticos especialmente preocupados de los proyectos educacionales para Chile, se formaron como abogados en la Real Universidad de San Marcos. Ambos fueron fervientes admiradores de los pensadores antiguos e ilustrados, cuya influencia se vio plasmada en sus propios proyectos. Al regresar a Chile, Juan Egaña se integró a la Universidad de San Felipe, donde fue nombrado consiliario menor y en 1802, catedrático de Latinidad y Retórica, temática propuesta por él mismo para emular el "buen gusto europeo". Su plan de estudios proponía abordar la poesía y la prosa latinas, así como conocer a los autores romanos para promover su imitación -especialmente la de Cicerón- en el desarrollo de textos castellanos ${ }^{7}$.

Más allá de la evidente lejanía o del relativo aislamiento de Chile respecto a Europa, la formación de estos intelectuales en los márgenes del sistema colonial explicaría que hubieran podido familiarizarse con ideas liberales y con un lenguaje asociado a categorías como aquellas sobre los derechos del hombre, el gobierno representativo o la soberanía popular, tan propios del discurso revolucionario y del movimiento ilustrado.

Los criollos que encabezaron los procesos políticos de Chile desde la instauración de la primera Junta Nacional de Gobierno (1810), hasta la declaración de la Independencia (1818), pudieron inspirarse en ideas provenientes de otras latitudes y gozar de un acervo cultural superior al que las condiciones del sistema educacional en Chile, per se, hubieran podido ofrecerles. Tal como afirma J. Myers, entre 1780 -con las revoluciones norteamericana y francesa- y 1820 , los escritores públicos hispanoamericanos, enmarcados hasta entonces por el orden cultural y académico español, fueron objeto de una transformación que originó para ellos una categoría particular: la del letrado patriota ${ }^{8}$.

Esta categoría bien puede albergar a quienes protagonizaron militar, política e intelectualmente los procesos independentistas y la construcción de sus respectivos Estados nacionales. Sus roles no fueron excluyentes; por el contrario, su interrelación

5 Carta de José Antonio de Rojas a Judas José de Salas, 7 de junio de 1775. En Amunátegui, 1876, p. 48.

6 Medina, 1887, pp. 535-537; Urbina, 2011, pp. 9-11; Píriz, 2012, pp. 18-22.

7 Silva Castro, 1959, pp. 19-23; Amunátegui, 1889, pp. 5-6.

8 Myers, 2008, p. 121. 
se hizo histórica e ideológicamente necesaria. Después de todo, la comunidad de letrados patriotas se originó en el seno de grupos social y políticamente influyentes, y a partir de allí asumieron la causa emancipadora y republicana en todas sus dimensiones, como un proyecto propio, al contar con la instrucción militar y la formación intelectual para protagonizar este proceso.

De esta manera, los mismos líderes que protagonizaron en Chile la conformación del primer Congreso Nacional, y que en numerosos casos participaron también de las acciones militares, fueron quienes llevaron al papel sus propuestas políticas y gubernamentales, no sólo mediante oficios concretos o libelos normativos, sino a través del ejercicio retórico de la elaboración de tratados, ensayos y debates editoriales. Tales documentos, en su dimensión literaria, constituyen una fuente valiosa para el conocimiento del imaginario y de la cosmovisión de estos patriotas, así como también y por consiguiente, para la comprensión del universo cultural que alimentó sus decisiones, fundamentó sus acciones e inspiró los proyectos políticos para la nueva nación ${ }^{9}$.

En este sentido, la historia política de la Independencia se funda sobre una historia cultural. Ésta dejó su huella en la literatura de la época, especialmente en la prosa periodística y en la retórica discursiva, géneros que si bien podrían no parecer propios de un quehacer literario convencional, eran los más adecuados a las necesidades del contexto y de sus protagonistas. A través de ellos se canalizaron intereses, preocupaciones y aspiraciones de los patriotas, constituyéndose en espacio y vehículo para las construcciones identitarias de las nuevas naciones, encabezadas por los líderes intelectuales.

Todos ellos tenían una concepción enciclopédica y no restrictiva de lo literario, que iba mucho más allá de lo que entonces se entendía por las 'bellas letras'. Literatura era no sólo la expresión imaginaria, sino toda expresión escrita, y aún más, toda actividad letrada que tuviese un fin edificante, que apuntara a transformar los residuos de la mentalidad colonial en virtudes cívicas y en una nueva conciencia nacional ${ }^{10}$.

La producción escrita de los letrados patriotas posee, por tanto, alcances que trascienden su dimensión explícita y discursiva. No constituían sólo un ejercicio teórico escindido de la práctica política, sino la fundamentación textual para la legitimación y ejecución de la acción concreta en el proceso emancipador, lo que implica al mismo tiempo, una dimensión cultural que trasciende el plano de las ideas políticas y de la historia intelectual.

Tal como ha observado Bernardo Subercaseaux en sus estudios relativos a la historia del libro y de la lectura en Chile, la primera generación de criollos ilustrados no puede ser entendida desde una perspectiva política escindida de su actividad intelectual y cultural. Se trataba de intelectuales polifacéticos, que entendieron lo literario de un modo enciclopédico y no restrictivo, vinculado por tanto a su quehacer político ${ }^{11}$.

El enfoque de Subercaseaux constituye un aporte al estudio de este periodo desde un enfoque cultural, en la medida en que la formación de esta comunidad criolla, de

\footnotetext{
9 Carrilla, 1964, p. 9.

10 Subercaseaux, 2013, p. 20.

11 Ibídem, pp. 19-20.
} 
sus ideas emancipadoras e ideales republicanos, ha sido analizada, en cambio, sobre todo desde la perspectiva de una historia intelectual o de las ideas políticas. Los estudios relativos a los fundamentos ideológicos de los discursos patriotas se han orientado a constatar las corrientes de influencia para comprender la naturaleza política e ideológica de sus proyectos, centrando su atención en el resultado de la propuesta, antes que en su contexto y sus fundamentos previos.

Proponiendo abocarse a un re-examen de la interacción entre ideas y política, Simon Collier, por ejemplo, analizó la evolución de los conceptos que sostuvieron al proceso revolucionario chileno, permitiendo la legitimación del sistema republicano sobre la base de una ideología liberal ${ }^{12}$. Las influencias que habrían permitido forjar el proyecto criollo fueron consideradas por el autor, como antecedentes para la valoración del mismo. Dicho proyecto permitiría identificar a los patriotas letrados como miembros de una misma comunidad intelectual, fundada en relación a su ideario. Es este último el que resulta, en consecuencia, objeto final de análisis.

Tal planteamiento es considerado también por Eduardo Cavieres, al analizar la pertinencia y el sentido de las categorías "liberal" y "republicano" para los políticos e intelectuales de la independencia ${ }^{13}$. Para eso, su estudio se enfoca principalmente en los discursos contemporáneos, lo que permite concluir que tales categorías sólo se resolverían en una definición distante de una adscripción ideológica definitiva. Las opciones políticas de los letrados patriotas se habrían definido a lo largo del proceso, mediante la idealización de algunos referentes del pasado remoto y reciente ${ }^{14}$.

Desde esta perspectiva, la tesis de Cavieres puede complementarse con la de Alfredo Jocelyn-Holt, en la medida en que ha analizado el proceso independentista como uno que, si bien constituyó un hito específico de la historia de Chile, conformó a su vez un proceso de largo aliento, al haber combinado elementos tradicionales y modernos en su desarrollo. Para Jocelyn-Holt, la elite chilena no habría aspirado a un proceso revolucionario, sino modernizador, lo que permite comprenderlo en relación al diálogo que sus actores sostuvieron con los aspectos del pasado ${ }^{15}$.

Las conclusiones de estos autores se fundan, de este modo, sobre el análisis de una historia de las ideas que permite afirmar la historicidad del proceso intelectual para la legitimación de la emancipación y la fundación del proyecto republicano chileno. Los modelos escogidos por la comunidad criolla no responderían a determinaciones ideológicas establecidas a priori y artificialmente. Por el contrario, habrían sido obje-

12 Collier, 2012, p. 29.

13 Cavieres, 2012, pp. 260-263.

14 Ibídem, p. 281. Así también puede inferirse de la propuesta de Roberto Breña, y de los análisis realizados por Ana María Stuven y Gabriel Cid, el dar cuenta de la contraposición de ideas que configuró el debate y las definiciones políticas de la república chilena en sus primeras décadas. BreÑA, 2004, pp. 9-12; STUVEN y CID, 2012, I.

15 Jocelyn-Holt, 1992, pp. 216-217. Para este autor, el pronunciamiento historiográfico respecto al rol y a la relevancia de la tradición y el cambio en el proceso de independencia se ha visto influido por las corrientes conservadoras o liberales que lo sostengan. De este modo, Jocelyn-Holt se refiere al concepto de "mito" como un recurso para la validación de los supuestos interpretativos de dichas corrientes, que se habrían generado durante el proceso mismo de la Independencia (312-319). 
to de una apropiación activa en el transcurso del mismo proceso $^{16}$. Esto permite afirmar, por tanto, que la interacción entre el discurso liberal y la acción emancipadora y republicana puede explicarse con mayor amplitud trascendiendo el plano de las ideas políticas, mediante la consideración de los discursos y prácticas como expresiones de un mismo universo cultural, que les confirió un sentido unívoco y unitario.

La reiteración de ciertos conceptos y la evocación a algunos modelos -como el romano, el norteamericano o el francés-, no pueden comprenderse sólo como un ejercicio intelectual de imitación mecánica de ideas previas y abstractas, sino como un fenómeno de apropiación activa de conceptos, valores y motivos, posibilitado por el bagaje cultural de la comunidad criolla. Los procesos de producción y representación de los proyectos políticos criollos se habrían cimentado sobre sus experiencias vitales e intelectuales, su mentalidad e imaginarios. Sus propuestas y acciones políticas pueden comprenderse así en un sentido más amplio, de naturaleza cultural.

Desde esta perspectiva, la educación intelectual y el contexto formativo de los patriotas letrados constituyen un factor clave a considerar para identificar los principios de inteligibilidad de sus proyectos independentistas. Los documentos escritos por los miembros de esta comunidad no sólo ofrecerían un testimonio para el conocimiento de sus proyectos, sino que mediante ellos, se constituirían también en evidencias de su cosmovisión y de los factores que incidieron para su configuración.

Así como las ideas sobre la Independencia y los ideales sobre la república se manifestaron en los textos criollos, la lectura de los libros que alimentaron el imaginario emancipador y republicano de esos autores se manifestó igualmente en la Independencia.

En este sentido, los letrados patriotas fueron autores de discursos y representaciones retóricas comunes, en cuanto constituyeron a su vez una comunidad de lectores. Como autores, habrían escrito sus propias obras en base a lo que, en cuanto lectores, refiguraron de las lecturas realizadas durante su experiencias de formación ${ }^{17}$.

Tal como afirma Roger Chartier, la lectura posee una dimensión que hace de ella un ejercicio de invención y producción de significaciones, determinado por el contexto de lectura o mundo del lector ${ }^{18}$. Los textos criollos relativos a la Independencia y a la fundación de la república chilena, podrían comprenderse así como el producto creativo de una comunidad de interpretación ${ }^{19}$, compuesta por quienes compartieron roles, experiencias y visiones, influidas por sus lecturas formativas, e influyentes sobre el modo de apropiarse de los textos leídos y de integrarlos en función de sus proyectos políticos.

La categoría del letrado patriota se presenta así como la del intelectual que asumió el rol de vocería de los ideales propios de una elite criolla, su comunidad de interpretación, como representantes de los intereses de la patria. Se trataba de un grupo de preeminencia social, que participando activamente en la lucha por la Independencia,

16 Por esta razón, no sería posible distinguir si una influencia como la francesa revolucionaria, hubiera podido incidir más que otra, como la norteamericana, sino que todas habrían convergido en un nuevo proyecto histórico. GAZMURI, 1990, pp. 183-185.

17 Ricoeur, 1985, II, p. 231.

18 Chartier, 2000, p. 51.

19 Cavallo y Chartier, 2004, pp. 16-20; Subercaseaux, 2013, pp. 23-26. 
lideró una avanzada intelectual que se plasmó en la prosa periodística como vehículo de sus ideas ${ }^{20}$.

De este modo, surgía una identidad cultural resultante del transcurso de un proceso formativo y de un contexto intelectual definido por las tendencias europeas modernas, los antecedentes históricos de sistemas y revoluciones precedentes, y las prácticas de lectura que albergaban tales ejemplos como modelos a seguir. Las propuestas y declamaciones políticas de estos patriotas se constituyen así en fuentes de su universo cultural.

\section{LECTURAS Y MODELOS INTELECTUALES DE LOS PATRIOTAS}

Tradicionalmente, los códigos, ideales y valores propios de la comunidad intelectual de chilenos patriotas han sido analizados a la luz de su formación en un contexto de tendencias ilustradas, racionalistas y revolucionarias. Parece incuestionable que el pensamiento de Voltaire, Rousseau y Montesquieu, principalmente, y los ejemplos de las revoluciones francesa y norteamericana influyeron en la conformación de sus imaginarios y en su manifestación posterior: la representación de sus proyectos plasmada en su propia producción escrita.

El interés por los representantes del pensamiento moderno ilustrado es evidente. Así, por ejemplo, mientras Medina sugiere que Camilo Henríquez se habría visto vinculado a un juicio de la Inquisición limeña relacionado a la lectura de tales autores, José Antonio de Rojas se habría arriesgado a embarcar hacia Chile una docena de cajas de libros que incluían títulos de Diderot y D’Alembert, Rousseau, Robertson, Montesquieu y Voltaire ${ }^{21}$.

No obstante, las lecturas de estos criollos no se habrían limitado a los textos escritos hacia el siglo XVIII. Su formación se amplió a las obras constitutivas del pensamiento y de la cultura de la tradición occidental, cuya relevancia fue igualmente reconocida por los autores ilustrados. Así, ya fuera de manera implícita o bien por la vía de una lectura directa, aunque quizás mediante una influencia menos evidente, los autores grecorromanos conformaron parte del canon referencial que inspiró el ideario emancipador y republicano de la comunidad patriota.

Los programas educacionales que regían a las escuelas hacia fines de la colonia, no ofrecen un testimonio alentador respecto de la variedad temática de los libros a los que se podía tener acceso en Chile. Sin embargo, algunos registros de bibliotecas conventuales y particulares -que en Santiago llegaron a contener más de veinte mil volúmenes en su conjunto- permiten reconstruir una idea inicial respecto a la variedad de autores, títulos e intereses que ampliaron el horizonte cultural de los criollos letrados.

Hacia el siglo XVIII, las materias bibliográficas más comunes eran aquellas vinculadas a la teología y a la cultura, conformada esta última por temas relativos a filoso-

\footnotetext{
20 De la CruZ, 2008, pp. 137-139.

21 Amunátegui, 1876, II, p. 48; Subercaseaux, 2000, p. 14; Medina, 1887, II, pp. 535-537.
} 
fía, gramática, latinidad, retórica, letras clásicas y modernas, y enciclopedias. En la mayoría de estas áreas, los clásicos grecorromanos constituían obras referenciales ${ }^{22}$.

Desde el siglo XVI, las bibliotecas conventuales y públicas hispanoamericanas habían contado entre sus libros las obras de Aristóteles, Plutarco, Esopo, Virgilio, Juvenal, Séneca y Tito Livio, entre otros ${ }^{23}$. Así ocurría en México y Lima, donde pese a que pudieran considerarse como libros de la antigua tradición escolástica, los clásicos pervivían como potenciales objetos de resignificación.

En 1760 las pocas librerías en Lima sólo vendían obras de autores antiquísimos: diversas ediciones de Cicerón, ejemplares de la Biblia latina que Sebastián Gryfo imprimió en León en 1550; los "Tesoros de la lengua latina" que Roberto Stefano publicó en 1577; las obras de Donato y del Catón Cordubense; y los Comentarios de Fray Juan Policarpo; los centones de Virgilio; distintas ediciones de filosofía, historiadores y poetas griegos... ${ }^{24}$.

Los clásicos grecorromanos habían formado parte necesaria de las bibliotecas coloniales ${ }^{25}$. Sus principios, sin embargo, no constituían referencias para el sistema educativo hispano escolástico, al menos en un sentido ideológico, pero sus lecturas podrían explicarse por el modelo que ofrecían en términos técnicos, como referentes de retórica, de estética y ética.

En Chile, entre las bibliotecas personales, la de Francisco Antonio de Avaria, en 1797, incluía de Vida de Alejandro el Grande de Plutarco, Fábulas de Esopo, obras de Cicerón y de Virgilio. El inventario registraba también dos obras que, aludiendo en sus respectivos títulos al mundo grecorromano, desarrollaban un pensamiento ilustrado, racionalista y crítico: Comentarios políticos a los Anales de Tácito de Juan Alfonso de Lancina (1687), y las Aventuras de Telémaco de François Fénelon (1699), novela política que criticaba duramente el gobierno de Luis XIV ${ }^{26}$.

Las Aventuras de Telémaco fue también objeto de interés del criollo Manuel de Salas, quien a comienzos de 1781, fue citado a declarar ante el Comisario del Santo Oficio de Cádiz, por haber intentado llevar a Chile una serie de libros entre los que se consideraban títulos prohibidos. La lista declarada por Manuel de Salas incluía, entre sus 117 títulos, autores clásicos y obras relativas al mundo antiguo: Vidas de los filósofos antiguos, Historia de Catilina, Epístolas de Cicerón, Comentarios de Julio César, la obra de Quinto Curcio, las Comedias de Terencio y la Historia Romana de Echard $^{27}$.

Esto no quiere decir que la lectura de tales libros estuviera prohibida por la Corona española. Los libros cuestionados a Manuel de Salas eran aquellos ligados al pensamiento moderno ilustrado, mientras que los autores clásicos grecorromanos eran materia de estudio por su valor moral o retórico. El inventario de la biblioteca jesuita del

\footnotetext{
22 Rípodas, 1989, p. 478; Earle, 2004, p. 40.

23 MartíneZ, 1987, p. 51.

24 Barreda, 1964, p. 214.

25 OSORIO, 1980.

26 Fondo Escribanos, 1797, vol. 935 (Andrés Manuel de Villarreal), 119 vta. Archivo Histórico Nacional

27 Eyzaguirre, 1957, pp. 9-11.
} de Chile. 
Colegio Máximo de San Miguel de 1767, por ejemplo, registraba entre los cajones las obras de Virgilio, de Ausonio, de Juvenal, de Marcial, el Agrícola y la Germania de Tácito, la Historia de Heródoto, la Geografía de Ptolomeo, la Architectura de Vitrubio, una traducción de Jenofonte, y las obras de Plutarco, Tito Livio, Cicerón, Apuleyo y Aristóteles ${ }^{28}$.

Por su parte, la biblioteca del Convento Máximo de San Agustín habría llegado a tener, hacia fines del periodo colonial, casi tres mil volúmenes. Entre ellos, los títulos de naturaleza religiosa y teológica habrían alcanzado los 1743 libros, mientras que los volúmenes referidos a Derecho Civil y Canónico contaban 748. Los restantes 473 se repartían entre obras enciclopédicas (60), históricas (259), diccionarios (51) y autores antiguos selectos $(103)^{29}$.

Las materias de clasificación y sus proporciones eran similares para el caso de la biblioteca de San Francisco hacia 1799. De sus 3032 volúmenes, las obras relativas a materias religiosas, teológicas y morales contaban los 2015 títulos, las juristas sólo alcanzaban los 181, las referidas a historia profana y sagrada, los 227 , y las obras humanistas, los $91^{30}$.

Es evidente que la cantidad de títulos vinculados al mundo antiguo era muy menor en relación al alto número de obras de naturaleza teológica y legislativa en estas bibliotecas. No obstante, su presencia y la escasa variedad de otros ámbitos incluidos en estas colecciones, dan cuenta del conocimiento y consideración sobre estos autores del humanismo antiguo, que luego trascendería en la producción escrita de los mismos criollos, relativizando el hecho de que fueran proporcionalmente pocos.

Algunos tratados modernos, por lo demás, incluían en su interior la transcripción de textos grecorromanos, recurso que pudo haber servido a la legitimación del nuevo texto que se publicaba y que aumentaba indirectamente las existencias bibliográficas de clásicos en las bibliotecas coloniales ${ }^{31}$.

Además, las publicaciones relacionadas con temáticas de carácter secular, sobre todo de naturaleza política, comenzaron a aumentar durante la primera década del siglo XIX, decreciendo proporcionalmente las de materia religiosa ${ }^{32}$. Señal de esto se evidenciaba en las traducciones, que en España a partir de 1789 no sólo fueron frecuentes sobre el latín y el francés, sino que dieron espacio paulatino al italiano y al griego, con la traducción de Plutarco, Hipócrates o Píndaro, por ejemplo. La cultura comenzaba a secularizarse ${ }^{33}$.

Las obras clásicas grecorromanas registradas en los inventarios de las bibliotecas chilenas hacia fines del siglo XVIII suelen reiterar los nombres de algunos autores que durante el proceso independentista, serían frecuentemente citados o evocados por

\footnotetext{
28 "Inventario de los libros encontrados en el Colegio de San Miguel”, 1767, vol. 7, p. 4, n 2353, Fondo Jesuitas, Archivo Histórico Nacional de Chile.

29 Thayer OJedA, 1913, V, pp. 4-5.

30 Ibídem, V, p. 5.

31 Ejemplo de esto lo ofrecen tratados retóricos, como la Explicación del tiempo o quantidad de la syllaba de Santiago de Zamora, publicado en México en 1725, que contenía en su cuarta parte la transcripción de De arte poetica ad Pisones, de Horacio. Por su parte, la obra de Pedro Reynoso y Rivera, publicada en México en 1712 con el título Illustrium autorum flores ad usum studiosae iuventutis, contenía las Philippicas de Cicerón.

32 EArle, 2004, pp. 26-29.

33 García Rojo, 2000, pp. 45-46.
} 
los intelectuales criollos: Aristóteles, Cicerón, Virgilio, Tito Livio y Plutarco, entre otros, mientras que algunos personajes históricos, como Licurgo, Solón, Escipión, César y Catilina, serían igualmente mencionados. Una de las primeras donaciones realizadas por Feliciano Letelier a la incipiente Biblioteca Nacional de Chile incluía, entre las diez obras ofrecidas, las Fábulas de Esopo y dos tomos de las Epistolas de Cicerón ${ }^{34}$. La donación de Manuel de Salas a la misma biblioteca registraba en 1832 la Retórica y Epistolas de Cicerón, Las Leyes de Platón (en francés), las Décadas de Tito Livio (en castellano), las comedias en latín de Terencio, las Metamorfosis de Ovidio (en italiano), los Comentarios de César (en castellano), la Historia Natural de Plinio (en latín) y las Epistolas de Séneca (en latín) ${ }^{35}$.

La recurrencia de estos nombres en estas bibliotecas y la presencia constante del pensamiento clásico grecorromano en la producción escrita de los intelectuales criollos -tal como se demostrará- sugiere que para entonces la tradición clásica comenzaba a revitalizarse como referente cultural y modelo para la representación de los nuevos proyectos republicanos. Y tal fenómeno no parece casual.

\section{TRADICIÓN CLÁSICA EN CHILE A COMIENZOS DEL SIGLO XIX}

La tradición se define como una conservación del pasado, aunque no siempre consciente, que ofrece las voces de épocas pretéritas y su bagaje cultural para tiempos posteriores, de manera que éstos las asuman como voces propias. La tradición, por tanto, no constituye el pasado en sí ni un patrimonio inmóvil, sino la mediación entre diversos periodos históricos.

El concepto de lo clásico puede ser definido en el mismo sentido, esto es, como el objeto que resulta de tal proceso: "Es clásico lo que se mantiene frente a la crítica histórica, porque su dominio histórico, el poder vinculante de su validez transmitida y conservada, va por delante de toda reflexión histórica y se mantiene en medio de ésta" 36 .

Desde esta perspectiva, los clásicos han sido objeto de recuperación y revaloración a lo largo de la historia cultural, en la medida en que, a partir de sucesivas lecturas, se ha ejercido sobre ellos un trabajo de modernización y actualización, entendiendo por esto la operación intelectual que los ha revestido de una o más significaciones al nivel de la conciencia histórica y de las prácticas culturales de cada periodo que los ha cultivado ${ }^{37}$.

En cuanto modelo político, la recepción y apropiación del pensamiento clásico había sido revalorado en diversas épocas y en distintos contextos, pues se ofrecía

\footnotetext{
34 El Monitor Araucano, $\mathrm{n}^{\circ}$ 68, 14 de septiembre de 1813. Cicerón, en particular, fue un autor sumamente influyente, al haber sido objeto de estudio para la enseñanza del latín, lengua que, para 1810, llenaba estanterías de las diversas bibliotecas y se dictaba en cátedras universitarias, inspirando también las citas ilustres de los tratados escritos en idioma castellano.

35 "Salas, Manuel de. Venta de libros a la Biblioteca Nacional", 1832, vol. 692, p. 1-14 fs., Fondos Varios, Archivo Histórico Nacional de Chile.

36 Gadamer, 2003, p. 356.

37 Marino, 1979, p. 77.
} 
como un recurso que pareciera haber producido textos para hablar a los lectores de otro presente, al sugerir como punto de partida, necesidades e inquietudes, al menos en apariencia, universales: la preocupación por establecer un orden, por aspirar a la estabilidad y por garantizar espacios de participación, ofreciendo así una respuesta a problemas heredados ${ }^{38}$.

La posibilidad de un proceso de recepción de los clásicos grecorromanos y de la influencia de la tradición clásica en Chile hacia el siglo XIX, en el contexto de una intelectualidad ilustrada y racionalista, y de un proceso político emancipador, debe comprenderse a partir de estas consideraciones. La lectura de las obras de la Antigüedad, la apropiación de sus discursos y la configuración de sentidos a partir de tal matriz, habrían consistido en un ejercicio de apropiación activa y productiva, un proceso de creación continua, esencialmente histórica, para la realización en el tiempo de su afirmación y cultivo ${ }^{39}$.

La influencia de la tradición clásica en la producción escrita de los patriotas letrados implicó un proceso de re-significación del humanismo grecorromano, por parte de esta comunidad de interpretación, una actividad re-configuradora de los bienes culturales legados por las obras de la Antigüedad, conservadas en las bibliotecas y las prácticas de lectura de estos intelectuales criollos.

La educación de los patriotas a la luz de los textos clásicos e ilustrados no resultó en una formación intelectual abstracta y contemplativa, sino en un fenómeno aplicado. Por este mismo motivo, sus pensamientos, reflexiones y propuestas no se volcaron en una producción literaria de naturaleza artística, sino en la redacción de periódicos, columnas editoriales, discurso y proclamas, que esperaban impactar en una dimensión fáctica.

De este modo, la presencia de la tradición clásica sobre el imaginario político y cultural plasmado en los proyectos y tratados republicanos de los criollos letrados, fue original y creativa, toda vez que se vio influida por un "filtro" particular" ${ }^{40}$ : el contexto de la Independencia hispanoamericana. De dicho proceso de recepción y resignificación se forjaría a partir de 1810 , una cultura política que cimentaría los primeros proyectos para la configuración de una nación y la organización del Estado.

Después de todo, las obras clásicas grecorromanas debieron haber sido objeto de lectura durante los siglos XVII y XVIII en Chile, pero su recepción durante el periodo colonial fue diferente y más pasiva. A inicios del siglo XIX, en cambio, las condiciones históricas habrían favorecido una recepción diferente. Por una parte, se fortalecía desde Europa la tendencia intelectual neoclasicista, que se había iniciado durante el siglo XVIII para hacerse notar en los proyectos educacionales -como en planes universitarios- y en prácticas culturales. La retórica romana, por ejemplo, fue revitalizada entre 1720 y 1840 en los planes de estudios superiores, promoviéndose la lectura y el debate a partir de los tratados y discursos de Cicerón, escritos en latín o traducidos en lenguas romances ${ }^{41}$.

\footnotetext{
38 Du Bois, 2010, pp. 173-175.

39 Calvino, 1991, p. 15; Highet, 1996, p. 11; Burke, 2007, p. 162.

40 Burke, 2000, p. 17.

41 Kennedy, 1995, p. 265.
} 
La corriente neoclasicista se habría proyectado luego desde el universo intelectual y artístico a los espacios, discursos y prácticas políticas. En Francia, la Tercera República pudo verse a sí misma en el reflejo de un sistema "clásico", retomando la idea de la nación en relación con un pasado idealizado por la idea de una gloria legendaria:

Et en ces sens, l'organisation institutionelle et intellectuelle d'une France hiérarchisée et profondément burocratique encourage l'éclosion du modéle antique dans ses formes les plus spirituelles ${ }^{42}$.

Así también, los primeros proyectos políticos gestados en el contexto de la Independencia norteamericana dan cuenta de la recepción activa de los modelos clásicos antiguos, en un contexto de clara influencia humanista y neoclásica ${ }^{43}$. Si bien los proyectos constitucionales posteriores se encaminarían hacia un sistema moderno liberal, las tesis republicanas fueron decisivas en los primeros programas políticos norteamericanos. "El uso de la Antigüedad no es un epifenómeno irrelevante, sino un instrumento profundamente arraigado en la práctica política de la América de finales del siglo XVIII" 44 .

Igualmente, las tendencias educacionales, culturales y políticas de Europa y Norteamérica influyeron sobre los patriotas letrados hispanoamericanos y de Chile, entre fines del siglo XVIII y comienzos del XIX, situándolos en un contexto cultural más amplio, dado por la tradición del mundo intelectual occidental.

A ello se agregaría una segunda variable histórica que permitiría comprender las circunstancias que posibilitaron la renovación de la lectura y de la apropiación de los clásicos. El siglo XIX se abría en Hispanoamérica, y específicamente en Chile, en el marco de un contexto no sólo independentista, sino también fundacional. La independencia a la que los líderes criollos aspiraban exigía al mismo tiempo generar un proyecto político que no sólo garantizara la correcta organización del nuevo Estado, sino que también, y primeramente, legitimara los derechos de autonomía y de soberanía nacionales.

Los sucesos revolucionarios obligaron, en la práctica, a que los intelectuales criollos tuvieran que recurrir a la teoría política para justificar no sólo la revolución en sí, sino las acciones que de ella emanaron ${ }^{45}$.

No obstante, los proyectos independentistas y republicanos de Chile no pretendían proponerse a partir de bases absolutamente originales. Por el contrario, su legitimidad requería de bases históricamente ya validadas, y esto implicaba recurrir a argumentos, fundamentos y modelos que endosasen un reconocimiento previo y universal.

Chile no podía ampararse en su historia precedente, si precisamente necesitaba desligarse de su pasado hispánico. Por eso, durante los primeros años del proceso de independencia -entre 1810 y 1814-, los líderes patriotas se volcaron a otros casos y

\footnotetext{
42 Wright, 2012, p. 157.

43 Winterer, 2002, pp. 1-2; Ruiz, 2006, pp. 22-26.

44 Martínez, 2013, p. 12.

45 PírIz, 2012, p. 31.
} 
argumentos históricos que, al ser distantes temporal y geográficamente de su nación, pudieran ser objeto de una idealización política y moral para constituirse en fundamento y referente del proceso emancipador y del proyecto republicano.

En este contexto, podemos comprender el rol y el valor que la tradición clásica y la memoria de la historia antigua grecorromana pudieron jugar para la configuración de un discurso legitimador para los intereses de la comunidad patriota.

\section{HUMANISMO CÍVICO EN EL PROYECTO DE LOS PATRIOTAS LE- TRADOS}

Entendemos por humanismo cívico aquel "movimiento de intelectuales que redescubrieron y popularizaron unos ideales de patriotismo, gobierno popular y servicio público heredados de la antigua Grecia y de la República romana" ${ }^{46}$. Se trata de una tendencia que, integrándose al proceso de recepción y renovación de la tradición clásica, no sólo rescató la lectura de los clásicos para imitar su estilo o sus ideas, sino que se apropió de la ideología implícita en ellos para la configuración de sus ideales e imaginario propios ${ }^{47}$.

El 13 de mayo de 1812 fue publicado el prospecto de la Aurora de Chile, periódico editado por Camilo Henríquez para divulgar los discursos independentistas, y las propuestas y noticias relativas al proceso de configuración de una república autónoma, aludiendo constantemente al ejemplo de los clásicos.

En dicho prospecto, Henríquez señalaba:

Empezará a desaparecer, nuestra nulidad política; se irá sintiendo nuestra existencia civil: se admirarán los esfuersos de una administración sagáz, y activa, y las marabillas de nuestra regeneracion. La voz de la razon, y de la verdad se oyrán entre nosotros despues del triste, é insufrible silencio de tres siglos. ¡Ah! en aquellos siglos de opresion de barbarie, y tropelias de Socrates, Platon, Tulio, Seneca, hubieran sido arrastrados á las prisiones, y los Escritores mas celebres de Inglaterra, de Francia, de Alemania hubieran perecido sin misericordia entre nosotros ${ }^{48}$.

Los tiempos de la monarquía española eran concebidos como un pasado oscuro, ignorante y bárbaro, que sólo podía superarse a través de la luz de la razón, simbolizada por los nombres de los sabios de la Antigüedad clásica y por los ilustrados de la modernidad. Iluminados por ellos, los chilenos podrían constituirse en ciudadanos y refundar su nación.

La propuesta escrita por los letrados criollos adquiría así un rol histórico, al romper con el pasado reciente de Chile y forjar a su vez una filiación cultural con la línea

\footnotetext{
46 Ruiz, 2006, p. 23.

47 Por ideología entendemos el conjunto de ideas y valores que conforman el cuadro axiológico, político y cultural a partir del cual se concibe y se representa la realidad.

48 "Prospecto", Aurora de Chile, 13 de mayo de 1812, p. 1.
} 
genealógica más tradicional de la civilización occidental, sobre la base de los ideales rescatados por el humanismo cívico ${ }^{49}$.

Gran parte de estos ideales se recogen en las teorías republicanas, es decir, aquellas que consideran la civitas o politeia como la forma más elevada de realización humana, esto es, la condición de ciudadano libre mediante su participación voluntaria en el gobierno de su ciudad o estado, con miras a un bien común ${ }^{50}$.

Desde un primer momento los patriotas letrados, ideólogos de la emancipación y soberanía de Chile, se refirieron a su nación como una república, tal como ocurriría en la mayoría de las nuevas naciones americanas. La utilización de este concepto simbolizaba, en primer lugar, la antítesis frente a la idea de monarquía, que hasta cierto punto se concebía en este contexto como un gobierno despótico. En una monarquía, el rey ostenta una autoridad y detenta un poder que trasciende toda competencia del pueblo, lo que restringe la potencial libertad de este último. La república, en cambio, se formulaba desde la suposición de que el pueblo es soberano y por tanto, cualquier sistema que se erigiera a partir de este principio, debía velar por la libertad de sus ciudadanos.

Desde este prisma, Roma antigua constituía en el imaginario patriota, un paradigma histórico referencial. A partir de él era posible representar y legitimar simbólicamente los ideales criollos, estableciendo paralelos implícitos o expuestos, que homologaban en términos muy generales la situación revolucionaria y fundacional de Roma, con la misma condición en Chile:

Los Romanos quitaron del Consulado á Lucio Colatino, por que se apedillaba Tarquino, y acababan de expulsar á los despotas de ese nombre. El de Fernando para la Amèrica es mas ominoso y sangriento. Ella aspira à su independencia, con la qual es inconciliable aquel fantasma ${ }^{51}$.

Por este motivo, la república no sólo era concebida en cuanto antítesis del sistema monárquico, sino también como una realidad política idealizada y de valores inherentes, que permitiría a los patriotas establecer a futuro un orden legítimo, justo y virtuoso. El concepto no respondía a una selección azarosa o sólo al afán por replicar otro modelo político cualquiera. Las fuentes contemporáneas a los primeros años de la emancipación reflejan un uso del concepto república por parte de los patriotas, con una profunda conciencia de sus alcances políticos, originales e históricos, en el más amplio sentido.

49 En opinión de Álvaro Kaempfer, los letrados criollos asumían así un rol histórico, forjando una filiación cultural con la genealogía occidental. Camilo Henríquez, específicamente, habría participado en esta labor, ingresando por medio de los discursos planteados en sus periódicos, a un tiempo universal identificado en el anhelo de orden, cohesión y singularidad local. Similar observación realiza José Antonio Aguilar respecto a la rebelión inglesa, afirmando que como una medida de cautela por su constitución histórica y de evitar futuras rebeliones, los ingleses habrían recurrido a las fórmulas que la sabiduría del pasado pudo ofrecer para conservar a la comunidad política en el tiempo. Así se habrían refugiado en los modelos clásicos grecorromanos y renacentistas. KAEMPFER, 2006, pp. 125-127; AgUilar, 2002, p. 60.

50 Manin, 2002, p. 13.

51 El Semanario Republicano, no 4, 28 de agosto de 1813. 
La república fue concebida sobre la base de la definición que la tradición republicana clásica había cimentado, y que aludía a ella como un referente integral de implicancias administrativas, gubernamentales, civiles y morales.

Tal como señalábamos, desde la perspectiva de este paradigma el gobierno del Estado competía a la ciudadanía o a los representantes de ésta, en la medida en que la soberanía de la nación recaía en los ciudadanos. La delegación del poder en algunos representantes de asignación periódica respondería a necesidades administrativas, pero salvaguardaba la condición libre de los ciudadanos gobernados, que actuarían voluntariamente en beneficio de sí mismos y de la comunidad. Desde la mirada del humanismo cívico, el sistema republicano se concebía de este modo como la res publica había sido propuesta por los intelectuales romanos, y la polis había sido pensada por los filósofos griegos.

La definición ofrecida por Cicerón da cuenta de los alcances de este concepto:

Así pues, la cosa pública es lo que pertenece al pueblo, pero pueblo no es todo conjunto de hombres reunido de cualquier manera, sino el conjunto de una multitud asociada por un mismo derecho, que sirve a todos por igual (...) Así, pues, todo pueblo, que es tal conjunción de multitud, como he dicho, toda ciudad, que es el establecimiento de un pueblo, toda república, que, como he dicho, es lo que pertenece al pueblo, debe regirse, para poder perdurar, por un gobierno. Éste debe servir siempre y ante todo a aquella causa que lo es también de la formación de la ciudad ${ }^{52}$.

Cicerón, en particular, no constituiría sólo un modelo retórico, sino que sería considerado como "el autor culturalmente más amplio y su estilo, incomparable", pues sus escritos "respiraban libertad y amor a la república" 53 . Atendiendo a estos mismos principios, los patriotas letrados comenzarían a plantearse las posibilidades políticas que se abrían para la nueva nación.

Un ejemplo paradigmático lo ofrecen los ensayos y manifiestos de teoría política escritos durante este primer periodo del proceso independentista. En 1810 se divulgó el manuscrito titulado Catecismo Político Cristiano, asociado al seudónimo de José Amor de la Patria. El autor introducía su planteamiento con una pregunta que respondía al clásico planteamiento político sobre los posibles sistemas de gobierno: "¿Cuántas especies hai de gobiernos, quales son, y en qué consisten?” ${ }^{44}$.

Su intención se dirigía a criticar a los gobiernos despóticos -una de las tres categorías que distingue-, para validar en cambio a los gobiernos republicanos, que en su opinión podían ser aristocráticos, democráticos o mixtos. Sin aludir directamente a un referente teórico, el autor del catecismo daba continuidad a una inquietud y a una respuesta tradicional, que en este nuevo resultado conjugaba las soluciones que autores como Platón, Aristóteles, Polibio, Cicerón, Santo Tomás, Maquiavelo y Montesquieu habían ofrecido ${ }^{55}$.

52 CiCERÓN, I, pp. 39-40.

53 Hanisch, 1970, p. 54.

54 José Amor de la PATria, 1810, p. 1.

55 Hanisch, 1970, pp. 22-24; CoRvalán, 1996, pp. 23-24. 
Tal como estos pensadores ya habían propuesto, la república se presentaba como el modelo a admirar y a imitar, pues daba soberanía al pueblo y garantizaba de este modo, su libertad: "En las Republicas el Pueblo es el soberano: el Pueblo es el Rey, y todo lo que hace, lo hace en su beneficio, utilidad, y conveniencia" 56 .

La cita, de una validez contemporánea a las condiciones políticas de Chile para ese entonces, evocaba simultáneamente una reflexión clásica, que en afirmaciones como la que Polibio había realizado al referirse a la excepcionalidad de la República romana, parecía volverse trascendente a la historia:

En la constitución romana el pueblo, y sólo el pueblo, es el árbitro que concede honores o inflige castigos, el único puntal de dinastías y constituciones y, en una palabra, de toda la vida humana ${ }^{57}$.

Más allá de la multiplicidad de influencias que pueden identificarse en el catecismo, el espíritu que animaba la concepción de un fundamento para la idealización de la república era el que había inspirado también a los pensadores latinos, como Polibio y Cicerón. Aquel del beneficio común para los ciudadanos como necesidad y objetivo para la formación de una sociedad civil, y de la definición del pueblo como el depositario último de la soberanía.

Los ejemplos extraídos de la historia antigua complementan igualmente las ideas expuestas en el catecismo: el autor alude a los casos de Creta, Esparta y sobre todo, Roma, en sus momentos despóticos y republicanos:

Roma tubo Reyes y los espulsó por sus tiranías: se estableció la República que floreció por muchos siglos. Julio César la trastornó con los exércitos que le había confiado, y pretendió dominarla: Bruto y Casio lo mataron en el Senado por sola esta razón; pero ya no hai entre los hombres Brutos ni Casios, y todos se dejan ensillar. Augusto su sucesor, estableció la Monarquía con las armas, y con sus artificios, Tiberio, Neron, Domiciano y otros monstruos la tiranizaron ${ }^{58}$.

Aun cuando podría seguir tendencias retóricas, la alusión a estos pasajes históricos no parece responder sólo a un interés por replicar el estilo expositivo de los precedentes pensadores republicanos. La concatenación de ejemplos desde el mundo grecorromano, pasando por algunos medievales y fundamentalmente, por referencias modernas, engarzaba las aspiraciones hispanoamericanas a una tradición occidental históricamente legítima.

Dos años más tarde, la Aurora de Chile también publicaba un tratado con la teoría sobre las tres formas puras de gobierno, rescatando esta vez la distinción más clásica que ya Aristóteles, Cicerón y Polibio habían establecido sobre la base de la diferenciación entre la monarquía, la aristocracia y la democracia. La nota, además, se refería a los defectos inherentes a estos sistemas políticos, concluyendo, tal como Cicerón, que al no existir el modelo perfecto de gobierno, el mejor sistema era aquel

\footnotetext{
56 José Amor de la Patria, 1810, p. 2

57 Polibio, VI, 14, 4.

58 José Amor de la Patria, 1810, p. 3.
} 
que garantizara menos vicios. El planteamiento expuesto en la Aurora evocaba así lo que el pensador latino había formulado como base constituyente de la teoría del humanismo cívico.

Los vínculos intertextuales pueden ser ilustrativos:

Si la soberania reside plena, unica, y exclusivamente sobre la cabeza de un solo hombre, resulta una monarquia. El soberano recibe pues diferentes denominaciones, según la diferente forma de gobierno. En la democracia el soberano es el pueblo: en la aristocracia lo son los principales del estado: en la monarquia lo es el monarca, ò rey. (...) Todas estas formas de gobierno estan expuestas à gravisimos inconvenientes: todas estan sujetas è grandisimos vicios, mas ó menos perniciosos; (...): de modo que un gobierno que por su forma y constitucion tiene menos vicios, debe considerarse como el mas perfecto, y los pueblos deben estar tranquilos y satisfechos con el ${ }^{59}$.

Así, cuando uno solo tiene el gobierno de todas las cosas, llamamos rey a esa persona única y reino a la forma de tal república; cuando lo tienen unos pocos selectos, se dice que tal ciudad se rige por el arbitrio de los nobles; y, por último, es ciudad popular -así la llaman-aquella en la que todo lo puede el pueblo. (...) Cualquiera de estas tres formas, si sirve para mantener aquel vínculo que empezó a unir en sociedad pública a los hombres, no es perfecta ciertamente, ni ninguna de ellas, en mi opinión, es la mejor, pero sí es tolerable, y cada una puede tener ventajas sobre las otras ${ }^{60}$.

Los autores criollos no pretendían proponer, por tanto, un sistema político original ni generar ideas innovadoras. Por el contrario, su constante emulación a la tradición humanista cívica, apoyada en las referencias históricas del mundo antiguo, y de casos europeos contemporáneos, como el inglés, pudo haber respondido a un intento por insertarse en una solución de continuidad. La única renovación se realizaba en la apelación a un modelo republicano ideal, que había inspirado a sociedades como Roma, pero se vinculaba esta vez a las aspiraciones chilenas.

Por otra parte, la teoría de los tipos de gobierno y el ideal republicano no sólo ofrecían un ejemplo para garantizar una administración eficiente y equitativa, sino también para lograr el establecimiento de un gobierno éticamente correcto y de una ciudadanía virtuosa. Tal como Cicerón indicaba, la virtud del sistema se alcanzaba en la medida en que el pueblo se organizara para salvaguardar el beneficio común, buscando protección mediante las garantías de la ley y del derecho. La ciudadanía se concebía así desde el prisma de una sociedad en cuanto comunidad jurídica que aspiraba al bien común por medio del reconocimiento de la majestad de la ley.

Atendiendo a este ideal, los romanos constituían un referente político y moral a imitar. En septiembre de 1812, la Aurora de Chile aludía al valor del ciudadano y de la autoridad de la ley para la consolidación de la república latina como un ejemplo a seguir:

Los Romanos se distinguieron sobre todos los pueblos del mundo por la atencion escrupulosa de las autoridades en respetar y conservar inviolables los derechos de todos los individuos de la república. Alli nada habia mas respetable que la vida de un simple

\footnotetext{
59 Aurora de Chile, n 16,28 de mayo de 1812.

60 Cicerón, I, 40-41.
} 
ciudadano: para condenar à uno se necesitaba convocar toda la asamblea del pueblo. La magestad del senado, la autoridad de los consules estaban en esta en esta parte mui terminadas por la ley. Todo respiraba dentro de Roma, y en sus exercitos aquel respeto por el nombre Romano, que exaltaba su valor, y lo sostenia en los peligros ${ }^{61}$.

Tal como sugerían los pensadores romanos clásicos, la responsabilidad sobre la configuración de la república recaía en todos los ciudadanos. Más allá de que a partir de este principio se erigiera un gobierno democrático directo o representativo, el principio fundamental del republicanismo clásico se orientaba al diseño de un Estado que preservara la libertad de los ciudadanos, haciendo de ellos el principio constitutivo de la sociedad y los depositarios de su soberanía.

Por este motivo, diversas proclamas, notas y tratados definieron el patriotismo apelando a la necesidad de orientar los sacrificios y esfuerzos de todos y cada uno, en beneficio de la nueva nación:

El amor de la patria es el mas energico y delicioso de todos los sentimientos: su ardor es siempre sublime, y se aviva y aumenta en medio de las contradicciones. Ya no existia la magestad del pueblo Romano, pero Roma vivia siempre en el alma de Caton ${ }^{62}$.

La definición del concepto república suponía así una acepción axiológica que subyace y sostiene el aparato gubernamental, administrativo y organizativo que luego se propusiese. La conformación de una república requería necesariamente de una ciudadanía virtuosa para su correcto establecimiento y para proyectarse con estabilidad. A esto apelaban los patriotas letrados, apoyándose nuevamente en los casos que el pasado grecorromano ofrecía como un antecedente histórico a considerar si Chile pretendía asociarse a la tradición y genealogía histórica republicana.

En el Semanario Republicano, por ejemplo, se recordaba la tiranía de Pisístrato como un error cometido por los atenienses dada su carencia de virtudes políticas. Y luego concluía:

Estos documentos que nos presenta la experiencia de los siglos nos hacen ver que las Republicas solo pueden florecer por las virtudes de los Ciudadanos; y que es el mayor error, pretender el establecimiento de un Gobierno republicano en un pueblo vicioso y corrompido ${ }^{63}$.

Bajo estas reflexiones subyacía una ideología republicana que se originaba en las teorías clásicas. Aun cuando los sistemas administrativos que se propusieran para la organización del gobierno pudieran diferir de los casos históricos precedentes, la matriz de inspiración parece haber sido la misma, idea que se refuerza con los ejemplos utilizados para fortalecer el planteamiento. El republicanismo clásico, surgido en el contexto del pensamiento grecorromano y revalorado especialmente en tiempos

\footnotetext{
61 Aurora de Chile, $\mathrm{n}^{\circ}$ 30, 3 de septiembre de 1812. Otros ejemplos en Aurora de Chile, $\mathrm{n}^{\circ} 23,16$ de julio de 1812, $\mathrm{n}^{\circ}$ 26, 26 de agosto de 1812; El Semanario Republicano, n 4, 28 de agosto de 1813.

62 Aurora de Chile, $\mathrm{n}^{\circ}$ 26, 26 de agosto de 1812.

63 “Sobre los gobiernos republicanos", El Semanario Republicano, n 8, 25 de septiembre de 1813.
} 
renacentistas, ofrecía un principio de fundamentación para las propuestas políticas concretas.

El ejemplo histórico del pasado romano por medio de su mención explícita constituía de este modo un tópico narrativo cargado de un sentido ideológico. Su rol no se limitaba a ser estético u ornamental. Cada mención del mundo antiguo, y especialmente de Roma republicana, respondía a una lógica retórica, política y cultural coherente.

La prosa expuesta en los periódicos y catecismos de la época puede analizarse, en este sentido, desde sus lógicas literarias y discursivas. El estilo retórico que daba espacio a estas menciones y evocaciones suponía que este recurso literario fortalecía el sentido ideológico de los planteamientos expuestos por los patriotas letrados. A través de las referencias al mundo grecolatino y su asimilación al contexto independentista, las condiciones factuales del proceso de emancipación y de la configuración del Estado chileno se poetizaban, trascendiendo sus alcances técnicos e inmediatos, así como los particularismos del contexto. El proyecto criollo republicano se legitimaba de este modo, mediante los fundamentos otorgados por una tradición universalmente reconocible y admirable.

\section{CONSIDERACIONES FINALES}

La poetización de las propuestas políticas por medio de las evocaciones al mundo clásico, permitía a los autores y lectores criollos, comprender, representar y apreciar la lucha independentista y los proyectos republicanos desde las lógicas de un discurso de aspiración histórica y universal. El recurso literario podía servir de este modo a la comprensión y representación de proyectos históricamente novedosos para Chile, pero no así originales. Y esta condición era precisamente aquella que podía conferirles validez y legitimidad.

En un contexto histórico nuevo, de matices refundacionales, el valor del modelo ofrecido por la tradición clásica, especialmente por medio de las teorías republicanas rescatadas por el humanismo cívico, se explica por su adaptación y resignificación conforme a la cosmovisión de los patriotas letrados. Una cosmovisión que se había forjado a partir de una formación cultural e intelectual influida por las tendencias racionalistas y neoclásicas de fines del siglo XVIII, facilitada por los viajes y la educación recibida por estos miembros de la aristocracia criolla fuera de los límites de Chile.

La utilización de los recursos ofrecidos por los textos y ejemplos históricos grecorromanos revela ese ejercicio de apropiación y de recepción activa y creativa de los clásicos, cuyo carácter se confirma por la condición de posibilidad de adaptarse a las particularidades del contexto, esto es, a las necesidades y requerimientos propios de cada cultura y momento, sin perder por eso sus formas esenciales.

De este modo, los textos escritos por los patriotas letrados en su relación ideológica con el modelo de los clásicos no resultaría de un ejercicio artificial o de una imitación forzosa de las obras ofrecidas por la tradición. El hecho de que la influencia clásica se entrecruce además con otros modelos referenciales, como aquellos ofreci- 
dos por el ejemplo de naciones contemporáneas y revoluciones recientes, y las obras escritas por los pensadores ilustrados, confirma que se trató de un proceso de recepción cultural activa y genuina.

En este marco, sobre todo en los primeros años de emancipación, la tradición clásica no habría tenido un peso menor, sino decisivo. Antes de iniciar la tarea concreta de la configuración gubernamental y administrativa del Estado chileno, pudo haber sido necesario validar las intenciones autonomistas de esta nación y orientar las bases axiológicas o ideológicas sobre las que el Estado chileno se construiría. Atendiendo al contexto histórico de inicios del siglo XIX y a los testimonios de los mismos patriotas, es posible afirmar que el sistema político que se configuraría debía ser uno que garantizara la libertad de los ciudadanos chilenos, en contraposición a un recuerdo del pasado hispano como una época de opresión. La monarquía, derivada de esta última, no constituía, por tanto, una opción, del mismo modo como tampoco lo había sido para Roma, una vez superado el gobierno de los reyes etruscos.

En este sentido, es posible comprender el valor discursivo e ideológico de la tradición clásica. Su distancia geográfica y temporal frente al contexto de Chile a comienzos del siglo XIX habría favorecido su idealización como un modelo de legitimación incuestionable y la validación del proyecto republicano, contrapuesto al pasado reciente monárquico.

El proceso de emancipación de Chile habría ofrecido a los patriotas letrados un campo aplicado para llevar sus lecturas a una valoración práctica. Los desafíos militares y políticos constituyeron un escenario extremadamente singular, cuyas condiciones permitieron el establecimiento de una relación dialéctica e ideológica con el mundo antiguo. De este modo, la influencia de la tradición clásica puede ser comprendida como un fenómeno dinámico, que desde la teoría y la letra, tensó al mismo tiempo las prácticas y experiencias de la naciente república.

\section{FUENTES}

1812 Aurora de Chile. Periódico ministerial y político. Santiago. Biblioteca Nacional de Chile.

1813 El Semanario Republicano de Chile. Santiago. Biblioteca Nacional de Chile. 1813 El Monitor Araucano. Santiago. Biblioteca Nacional de Chile.

\section{CICERÓN}

2000 Sobre la República. Madrid. Gredos.

José AMOR DE LA PATRIA

1810 Catecismo político christiano, dispuesto para la instrucción de la juventud de los Pueblos libres de la América meridional. Manuscrito. Santiago. Biblioteca Nacional de Chile, www.memoriachilena.cl.

POLIBIO

2001 Historias. Madrid. Gredos. 


\section{REFERENCIAS BIBLIOGRÁFICAS}

Aguilar, José Antonio

2002 "Dos conceptos de República". En Agullar y Rojas, El republicanismo en Hispanoamérica. México. Fondo de Cultura Económica, pp. 57-85.

AmunÁtegui, Domingo

1876 La crónica de 1810. Santiago de Chile. Imprenta de la República de Jacinto Nuñez.

AmunÁtegui, Domingo

1889 Los primeros años del Instituto Nacional. Santiago de Chile. Imprenta Cervantes.

BARREDA, Felipe

1964 Vida intelectual del virreinato del Perú. Lima. Edición de la Universidad Nacional Mayor de San Marcos.

BREÑA, Roberto

2004 "Ideología, ideas y práctica política durante la emancipación de América: panorama del caso novohispano". Historia y Política. Madrid, nº 11, pp. 9-33.

Burke, Peter

2000 El Renacimiento europeo. Centros y periferias. Barcelona. Crítica.

BuRKe, Peter

2007 "La historia intelectual en la era del giro cultural". Primas. Quilmes, n 11, pp. 159-164.

Calvino, Ítalo

1991 Por qué leer los clásicos. Barcelona. Fábula.

CARrilla, Emilio

1964 La literatura de la independencia hispanoamericana. Buenos Aires. Eudeba.

CAVAllo, Guglielmo y Chartier, Roger

2004 Historia de la lectura en el mundo occidental. Madrid. Taurus.

CAVIERES, Eduardo

2012 Sobre la independencia de Chile. Valparaíso. Ediciones Universitarias de Valparaíso.

ChARTIER, Roger

2000 Las revoluciones de la cultura escrita. Diálogos e intervenciones. Barcelona. Gedisa.

ColLIER, Simon

2012 Ideas y política de la independencia chilena [1967]. Santiago de Chile. Fondo de Cultura Económica.

CORVALÁn, Luis

1996 "Catecismo Político Cristiano: ¿Unidad o diversidad doctrinal?”. Universum. Talca, $n^{\circ} 11$, pp. 23-30. 
De la Cruz Hermosilla, Emilio

2008 El periodismo y la emancipación de Hispanoamérica. Cádiz. Quorum Editores.

Du Bois, Page

2010 Out of Athens. London. Harvard University Press.

EARLE, Rebecca

2004 "El papel de la imprenta en las guerras de independencia de Hispanoamérica". En Soto, Entre tintas y plumas. Historias de la prensa chilena del siglo $X I X$. Santiago de Chile. Andros Impresores, pp. 19-43.

EyzAGUIRRE, Jaime

1957 Don Manuel de Salas procesado por la Inquisición. Santiago de Chile. Academia Chilena de la Historia.

GADAMER, Hans-Georg

2003 Verdad y Método. Salamanca. Sígueme.

García Rojo, Paz

2000 “QQué hay para leer en Madrid a fines del siglo XVIII?”. En MorÁN, La oferta literaria en Madrid (1789-1833). Un estudio cuantitativo de la cultura del libro. Madrid. CEES Ediciones, pp. 29-49.

Gazmuri, Cristián

1990 "Libros e ideas políticas francesas en la gestación de la independencia de Chile”. Caravelle. Toulouse, $\mathrm{n}^{\mathrm{o}}$ 54, pp. 179-207.

HANish EsPíndOLA, Walter

1970 El Catecismo Político-Cristiano: las ideas y la época, 1810. Santiago de Chile. Editorial Andrés Bello.

Highet, Gilbert

1996 La tradición clásica [1954]. México. Fondo de Cultura Económica.

JoCELYN-HoLt, Alfredo

1992 La independencia de Chile: tradición, modernización y mito. Madrid. Mapfre.

KAEMPFER, Álvaro

2006 "Periodismo, orden y cotidianidad: Presentación de la Gaceta de Buenos Aires de Mariano Moreno (1810) y Prospecto de la Aurora de Chile (1812) de Camilo Henríquez". Revista Iberoamericana. Pittsburgh, vol. LXII, no 214, pp. $125-138$.

Kennedy, George A.

1995 "La retórica". En Jenkyns, Richard, El legado de Roma. Una nueva valoración. Barcelona. Editorial Crítica, pp. 246-266.

MANIN, Bernard

2002 "Montesquieu, la república y el comercio". En Aguilar y Rojas, El republicanismo en Hispanoamérica. México. Fondo de Cultura Económica, pp. 1356. 
MARINO, Adrian

1979 "Intérpreter et/est moderniser les classiques". Les modèles classiques dans les littératures. Actes du IX Congrés de l'Association Internationale de Littératur Comparée. Innsbruck, pp. 77-82.

MarTínez, José Luis

1987 El libro en Hispanoamérica. Origen y desarrollo. Madrid. Pirámide.

Martínez Maza, Celia

2013 El espejo griego. Atenas, Esparta y las ligas griegas en la América del periodo constituyente (1786-1789). Barcelona. Edicions Bellaterra.

Medina, José Toribio

1887 Historia del Santo Oficio de la Inquisición en Chile. Santiago de Chile. Imprenta Gutenberg.

MYers, Jorge

2008 "El letrado patriota: los hombres de letras hispanoamericanos en la encrucijada del colapso del imperio español en América”. En Altamirano y Myers, Historia de los intelectuales en América Latina. Madrid. Katz, vol. I, pp. 121144.

OsoRIo, Ignacio

1980 Floresta de Gramática, Poética y retórica en Nueva España (1521-1767). México. Universidad Nacional Autónoma de México.

Píriz García de la Huerta, Francisco

2012 Camilo Henríquez. El patriota olvidado. Santiago de Chile. Ril Editores.

Ricoeur, Paul

1985 Temps et récit. Paris. Editions du Seuil.

RíPODAs, Daysi

1989 "Libros y lecturas en la época de la Ilustración”. En Historia general de España y América. América en el siglo XVIII. La Ilustración en América. Madrid. Rialp, Tomo XI-2, pp. 467-496.

Ruiz Ruiz, Ramón

2006 La tradición republicana. Renacimiento y ocaso del republicanismo clásico. Madrid. Dykinson.

Silva CAStro, Raúl

1959 Egaña en la Patria Vieja. 1810-1814. Santiago de Chile. Editorial Andrés Bello.

Subercaseaux, Bernardo

2000 Historia del libro en Chile (alma y cuerpo). Santiago de Chile. LOM.

2013 "Literatura y prensa de la independencia, independencia de la literatura". En CARrillo - Wehrheim, Literatura de la independencia, independencia de la literatura. Madrid. Iberoamericana, pp. 19-43.

Stuven, Ana María - Cid, Gabriel

2012 Debates republicanos en Chile. Santiago de Chile. Ediciones UDP. 
THAYer OJeDA, Tomás

1913 "Las bibliotecas coloniales de Chile". Revista de bibliografia chilena y extranjera. Santiago de Chile, año 1, números 1-10.

URBINA, José Leandro

2011 Camilo Henríquez. Santiago de Chile. Editorial Universidad de Santiago de Chile.

WINTERER, Caroline

2002 The culture of classicism. Ancient Greece and Rome in American intellectual life, 1780-1910. Baltimore. The Johns Hopkins University Press.

WRIGHT, Donald

2012 L'Antiquité Moderne. Paris. L'Harmattan. 